\title{
Combining use of embryo sexing and cloning within mixed MOETs for selection on dairy cattle
}

\author{
JJ Colleau \\ Institut National de la Recherche Agronomique, Station de Génétique Quantitative \\ et Appliquée, 78352 Jouy-en-Josas Cedex, France
}

(Received 17 September 1991; accepted 13 April 1992)

\begin{abstract}
Summary - Given the same overall number of transferred embryos, a comparison was carried out between adult mixed (ie with bull progeny-testing) MOET (multiple ovulation and embryo-transfer) schemes with embryo sexing only versus embryo sexing plus cloning of female embryos. In the former schemes, natural and ET (embryo transfer) animals were allowed to breed. In the latter schemes, each category of females (single born or cloned) was allowed to give birth either to new single animals (natural calvings) or to new clones (ET). The optimal structure (subpopulation sizes and corresponding selection pressures) in both schemes was derived algebraically by maximizing the predicted asymptotic annual genetic gains, assuming an infinite population but accounting for the Bulmer effect. Detailed presentation is given here for the case of embryo cloning (that of embryo sexing was dealt with in a previous paper). Schemes using the full reproductive capacity of a given genotype allowed by cloning were found to be superior $(+5$ to $+10 \%)$ when the number of live replicates per cloned heifer was moderate $(3-5)$. They were even more superior for higher number of replicates (10-20). This trend was confirmed by Monte-Carlo inbreeding-free (for the sake of consistency with the model) simulations. Some Monte-Carlo simulations accounting for inbreeding effect were carried out until year 100 after starting the breeding schemes. With 5 replicates per clone, the ultimate annual rates of increase of inbreeding were found to be still reasonable $(0.20$ to $0.25 \%)$. Using 10 replicates per clone would substantially increase these coefficients $(0.27$ to $0.33 \%)$, while still generating higher observed genetic gains. Consequently, keeping only 5 replicates would seem to be a reasonable comprise between increases in $F$ and in genetic gains.
\end{abstract}

dairy cattle / selection / genetic gains / embryo sexing / embryo cloning

Résumé - Utilisation conjointe du sexage et du clonage des embryons dans les MOETs mixtes fermés pour la sélection des bovins laitiers. On a comparé des schémas MOET (superovulation et transfert d'embryon) mixtes (c'est-à-dire conservant le testage des taureaux sur descendance) adultes avec sexage seul ou sexage et clonage des embryons femelles, en raisonnant à même nombre total d'embryons transférés. Dans les premiers schémas, les animaux normaux et issus de transplantation embryonnaire (TE) peuvent être 
reproducteurs. Dans les seconds, chaque catégorie de femelles (nées simples ou clonées) peut donner naissance soit à de nouveaux animaux simples (après vêlage naturel) soit $\grave{a}$ de nouveaux clones (TE). La structure optimale (tailles de sous-populations et pressions de sélection correspondantes) des 2 schémas a été calculée algébriquement en maximisant le gain génétique annuel asymptotique espéré. On supposait une population de grande taille mais on tenait compte de l'effet Bulmer. On donne ici la présentation détaillée de l'algorithme concernant le clonage, étant entendu que le cas du sexage a été traité dans un article précédent. Les schémas utilisant la pleine capacité reproductive des clones ont été trouvés supérieurs (5-10\%) quand le nombre de répliques vivantes d'une même génisse était modéré (3-5). Ils étaient encore supérieurs pour un nombre encore plus élevé de répliques (10-20). Cette tendance a été confirmée par des simulations aléatoires réalisées sans effets de consanguinité (par souci de cohérence avec le modèle). Quelques simulations aléatoires tenant compte de la consanguinité ont été effectuées jusqu'à l'année 100 après le début du programme de sélection. Avec 5 répliques par clone, le taux annuel final d'élévation de la consanguinité a été trouvé encore raisonnable (0,20-0,25\%). L'utilisation de 10 répliques par clone augmenterait sensiblement ces coefficients (0,27-0,33\%) mais permettrait encore d'augmenter les gains génétiques observés. En conséquence, l'utilisation de la première possibilité (5 répliques par clone) semblerait être un compromis acceptable entre l'augmentation du coefficient $F$ et celle du gain génétique.

bovins laitiers / sélection / progrès génétique / sexage d'embryon / clonage d'embryon

\section{INTRODUCTION}

The potential of using sexed clones within MOET (multiple ovulation and embryo transfert) schemes, either for enhancing the genetic gain within nuclei or for rapidly improving the average genetic level of the commercial population has already been pointed out and studied (Van Vleck, 1981; Nicholas and Smith, 1983; Smith, 1989; Teepker and Smith, 1989; Woolliams, 1989; De Boer and Van Arendonk, 1991).

The objective of the present study is to examine the prospect for mixed MOETs (ie MOETs keeping progeny testing) to improve their rates of genetic gain by using embryo cloning associated with embryo sexing, although the cloning technology is not yet available for animal breeding. A previous study (Colleau, 1991) has shown that in the same context of mixed MOETs, adult schemes with embryo sexing are good alternatives to juvenile schemes, provided that comparison is made at the same overall number of transferred embryos. Therefore, the present comparison becomes a comparison between adult schemes with embryo sexing versus adult schemes with embryo sexing and cloning given the same constraint.

This question is addressed by comparing assumed asymptotic linear rates of genetic gain under a Bulmer model (Bulmer, 1971), either calculated deterministically or observed through Monte-Carlo simulation. In this model, inbreeding is not accounted for. Therefore, attention is given mainly to situations where the number of clones selected for breeding is still high, $i e$, where the number of members of the same clone is moderate. 


\section{MATERIALS AND METHODS}

\section{Adult nucleus schemes with embryo sexing}

These schemes were those of a previous study (Colleau, 1985), where the trait selected for was assumed to be ruled only by additive genetic variation.

Each year, 130 young bulls coming from the nucleus entered the AI center. One hundred of them were actually progeny-tested, on 50 daughters per bull. The best 3 bulls, when proven at 5.5 years, were used for matings with the nucleus females. Usage period for these bulls was only 1 year.

Nucleus females were dispersed over farms enrolled in milk recording. Dams were selected from their sole first lactation record $i e$, the most difficult situation in order to test the robustness of the envisioned schemes. Replacement progeny, male or female, were allowed to come from the first 2 calvings and 2 additional embryo collections at the beginning of the second lactation (see table I).

Table I. Time schedule for nucleus females in the adult MOET with embryo sexing.

\begin{tabular}{ll}
\hline Period (mo) & Activity \\
\hline $0-9$ & $\begin{array}{l}\text { Waiting for the yield results of dams, except for females born from } \\
\text { adult ET (10\% mortality) }\end{array}$ \\
9 & Selection for nucleus replacement \\
24 & First calving after 2AI (10\% culling) \\
33 & Selection of dams of bulls and dams of cows \\
36 & Second calving after 2AI (10\% culling) \\
& Further selection of dams of bulls and dams of cows: for choosing \\
& natural second calves for replacement; for choosing the cows to be \\
$38-40$ & superovulated \\
48 & 2 embryos collection on the selected cows \\
& Birth of adult ET progeny \\
\hline
\end{tabular}

\section{Adult schemes with embryo sexing and cloning}

As in the adult schemes with embryo sexing, natural and ET calves were eligible for future breeding. Furthermore, the system is still a dispersed female nucleus.

Cloning of male embryos was avoided since inbreeding already originated mostly from the male side.

Cloning of female embryos was supposed to be successful for each original embryo and led to 2 categories of dams: single dams and cloned dams (ie, the whole population of several different clones with several members per clone). Since each dam might give birth to progeny 3 times in her life, 6 different categories of replacement animals of the same sex were obtained instead of 3 for embryo sexing without cloning (table II). The organization was therefore more cumbersome. For parsimony of notation, indices 1 to 3 will be attached to animals born from single dams and indices 4 to 6 to animals born from cloned dams. 
Table II. Distribution of the replacement groups ( 1 to 6 for each sex) according to dam and reproduction categories.

\begin{tabular}{|c|c|c|c|c|c|c|}
\hline \multirow{4}{*}{$\begin{array}{l}\text { Reproduction } \\
\text { category }\end{array}$} & \multicolumn{6}{|c|}{ Dam category } \\
\hline & \multicolumn{3}{|c|}{ Single } & \multicolumn{3}{|c|}{ Clone } \\
\hline & 2 & 3 & 4 & 2 & 3 & 4 \\
\hline & $y r$ & $y r$ & $y r$ & $y r$ & $y r$ & $y r$ \\
\hline Natural & $\mho^{\prime} 1$ & $O_{2}$ & - & $3^{7} 4$ & 35 & - \\
\hline Birth & ? 1 & q 2 & & P 4 & ? 5 & \\
\hline Sexed embryo & - & - & $O^{7} 3$ & - & - & $O^{7} 6$ \\
\hline $\begin{array}{l}\text { Cloned sexed } \\
\text { embryo }\end{array}$ & - & - & ㅇ 3 & - & - & P 6 \\
\hline
\end{tabular}

For each sex, replacement could be obtained from 6 categories:

Category 1: natural first calves born when the single dam is 2 years old and chosen 1 year later based on the dam's first lactation.

Category 2: natural second calves born when the single dam is 3 years old, based on the dam's first lactation.

Category 3: ET calves born when the single dam is 4 years old (on average, embryo collection done after 3 months of lactation during lactation 2).

Category 4: natural first calves born from 2 years old cloned dams, chosen 1 year later on the average first lactation of the corresponding clone.

Category 5: natural first calves born from 3 years old cloned dams, based on the average clonal first lactation.

Category 6: ET calves born from 4 years old cloned dams, based on the average clonal first lactation.

If the genetic standard deviation is taken as unit and if dams or clones are selected on their performance alone, the asymptotic annual genetic gain according to Rendel and Robertson's formula (1950) is equal to $\Delta G=u / v$ where

$$
\begin{gathered}
u=K_{1}+\frac{1}{M} \sum_{i=1}^{6} m_{i} \rho_{i} I_{t_{i}}+\frac{1}{F+c F^{\prime}} \sum_{i=1}^{6} f_{i} \rho_{i} I_{t_{i}^{*}} \\
v=K_{2}+\frac{1}{M} \sum_{i=1}^{6} m_{i} L_{i}+\frac{1}{F+c F^{\prime}} \sum_{i=1}^{6} f_{i} L_{i}
\end{gathered}
$$

$K_{1}$ : twice the genetic selection differential along the sire-son transmission path ( $K_{1}=3.98$ if no Bulmer effect is assumed) since the same bulls are used in the nucleus to produce either replacement males or females;

$K_{2}=$ twice the generation interval for the same path (13.5);

$\rho_{i}=$ accuracy of the dam's selection index;

$m_{i}$ : group size of the $i$ th category of replacement males;

$M=\sum_{i=1}^{6} m_{i}=$ Constant $=130$ throughout 
$f_{i}$ : group size of the $i$ th category of replacement females;

$F=f_{1}+f_{2}+f_{4}+f_{5}=$ overall number of single heifers chosen for replacement;

$F^{\prime}=\frac{1}{c}\left(f_{3}+f_{6}\right)=$ overall number of clones chosen for replacement;

$c$ : number of members per clone;

$t_{i}$ : selection threshold for dams of the $i$ th category of male replacements on a standard scale (mean equal to 0 and variance equal to 1 );

$t_{1}$ to $t_{3}$ are thresholds within the subcohort of singles;

$t_{4}$ to $t_{6}$ are thresholds within the subcohort of clones. Clones are considered as dummy cows obtained from pooling all the progeny and all the performances of the members of the same clone;

$t_{i}^{*}$ : selection threshold for dams of the $i$ th category of female replacements on the same scale. $t_{1}^{*}$ to $t_{3}^{*}$ involve the subcohort of singles and $t_{4}^{*}$ to $t_{6}^{*}$ the subcohort of dummy cows;

$p_{i}, p_{i}^{*}$ : corresponding probabilities that within the proper subcohort, the standardized performance of any possible candidate lies above the thresholds;

$I_{t_{i}}, I_{t_{i}^{*}}$ : standardized phenotypic selection differentials of the performances (supposedly unbiased by possible preferential treatments) of the dalis giving birth to the corresponding groups of each sex.

For calculating selection differentials, an infinite number of unrelated candidates to selection was assumed (conventional procedure). Since normality is assumed, $I_{t_{i}}$ equals $\phi_{t_{i}} / p_{i}$ where $\phi_{t_{i}}$ is the ordinate of the standardized normal distribution at point $t_{i}$.

Correspondingly, $I_{t_{i}^{*}}=\phi_{t_{i}^{*}} / p_{i}^{*}$.

$L_{i}=$ age of the dams (in years) for category $i$, whatever the sex of calves.

Longevity and reproduction parameters are needed for linking group sizes $\left(m_{i}, f_{i}\right)$ to the corresponding selection thresholds $\left(t_{i}, t_{i}^{*}\right)$. It can be readily shown that for $i=1$ to $3, p_{i}=m_{i} / F \theta_{i}$ and that for $i=4$ to $6, p_{i}=m_{i} / F^{\prime} \theta_{i}$. For $p_{i}^{*}$, replace $m_{i}$ by $f_{i}$, and $\theta_{i}$ by $\theta_{i}^{*}$.

$\theta_{i}$ is the expected available male progeny per initial single cow $(i \leq 3)$ or per initial dummy cow $(i>3)$, insisting on the fact that family size is not restricted (eg, 1 male per sibship or per sire).

$\theta_{i}^{*}$ is the expected available female progeny per initial single cow $(i \leq 3)$ or per initial dummy cow, with unrestricted family sizes.

Functional relationships are obvious: $\theta_{4}=c \theta_{1}, \theta_{5}=c \theta_{2}, \theta_{6}=c \theta_{3} ; \theta_{4}^{*}=c \theta_{1}^{*}, \theta_{5}^{*}=$ $c \theta_{2}^{*}, \theta_{6}^{*}=c \theta_{3}^{*}$ (dummy cows have more progeny) and $\theta_{3}^{*}=c \theta_{3}$ (female embryos are cloned and male embryos are not).

Let us take an example where the proportion of heifers able to calve $\left(\gamma_{1}\right)$ is 0.9 , the proportion of first calvers able to calve again is 0.9 , the proportion of the latter animals responding to superovulation is $0.7,10$ embryos $(2 \times 5)$ are collected per treated cow, the embryo survival rate is 0.6 , the calf survival rate is 0.9. Female embryos are cloned so that each live ET female is replicated 5 times. 
All the members of a selected clone are allowed to breed.

$$
\begin{aligned}
& \theta_{1}=0.9 \times 0.45=0.41 \\
& \theta_{2}=0.9 \times 0.9 \times 0.45=0.36 \\
& \theta_{3}=0.9 \times 0.9 \times 0.7 \times(10 / 0.7) \times 0.6 \times 0.5 \times 0.9=2.19 \\
& \theta_{4}=5 \theta_{1}=2.05 \\
& \theta_{5}=5 \theta_{2}=1.80 \\
& \theta_{6}=5 \theta_{3}=10.95 \\
& \theta_{1}^{*}=\theta_{1} \\
& \theta_{2}^{*}=\theta_{2} \\
& \theta_{3}^{*}=5 \theta_{3}=10.95 \\
& \theta_{4}^{*}=\theta_{4} \\
& \theta_{5}^{*}=\theta_{5} \\
& \theta_{6}^{*}=5 \theta_{6}=54.75
\end{aligned}
$$

The high value for $\theta_{6}^{*}$ originates from the fact that cloning acts twice for female ET progeny; firstly by multiplying the number of cows of a given genotype and secondly by multiplying their female progeny.

The accuracy of evaluation of the single dams is equal to $\rho_{1}=\rho_{2}=\rho_{3}=h$ (square root of the heritability). Since cloned females are dispersed over many farms with no common environmental effect, and the assumed genetic variation is only additive polygenic, then:

$$
\rho_{4}=\rho_{5}=\rho_{6}=\left(\frac{\gamma_{1} c h^{2}}{1+\left(\gamma_{1} c-1\right) h^{2}}\right)^{1 / 2}
$$

Because the constraints on the group sizes are linear $\left(\Sigma_{i} m_{i}=\right.$ constant; $m_{3}+m_{6}+f_{3}+f_{6}=$ fixed number of embryos transferred $\times$ survival rate $=$ constant), the annual genetic gains possible with a given combination are expressed in reference to these variates and the optimization of the non-linear function was performed according to a Newton-Raphson procedure ("inner" iteration) after eliminating 2 group sizes as a result of both constraints (The dependent variates are $m_{5}=M-m_{1}-m_{2}-m_{3}-m_{4}-m_{6}$ and $f_{6}=$ total number of transferred embryos $\times$ embryo survival rate $\times$ calf survival rate $-m_{3}-m_{6}-f_{3}$ ). This is considered as a safe procedure for converging towards a global maximum (Scales, 1985) when the corresponding derivatives can be analytically derived (see appendix). During this optimization, subgroup and clone numbers were allowed to be non-integer.

\section{Deterministic evaluation of the asymptotic rate of genetic gain under a Bulmer model}

Male and female populations were considered as infinite and selection differentials were computed accordingly. However, reduction of genetic variance through induced linkage disequilibrium (Bulmer effect) was accounted for. 
At the equilibrium, the genetic variance among unselected males $\left(V_{A M}\right.$ was equal to 0.5 initial genetic variance $\left(V_{A 0}\right)+0.25$ genetic variance among bull sires +0.25 genetic variance among bull dams.

The genetic variance among bull sires was equal to $V_{A M}\left(1-Z R_{M}^{2}\right)$ where $Z$ was the proportionate reduction of variance after selection among the estimated breeding values of sires and where $R_{M}^{2}$ was the squared accuracy of these EBVs.

$$
R_{M}^{2}=n /\left[n-1+4\left(V_{A F}+V_{E}\right) / V_{A M}\right]
$$

$n=$ number of daughters per bull for progeny-testing;

$V_{A F}=$ genetic variance among unselected females;

$V_{E}=$ environmental variance.

The genetic variance among bull dams was equal to:

$$
V_{A F}\left(1-\sum_{i=1}^{6} \frac{m_{i}}{M} W_{i} \rho_{i}^{2}\right)+V_{A F} \sum_{i=1}^{6} \frac{m_{i}}{M}\left(J_{t i}-\sum_{i=1}^{6} \frac{m_{i}}{M} J_{t i}\right)^{2}
$$

where: $W_{i}$ was the reduction of variance after selection among the estimated breeding values of dams of group $i$ males:

$$
\begin{aligned}
J_{t_{i}} & =\rho_{i} I_{t_{i}}-i \Delta G V_{A F}^{-1 / 2}+\varphi_{i} \\
\varphi_{i} & =0 \text { for } i \leq 3 \text { or } \mu V_{A F}^{-1 / 2} \text { for } i>3
\end{aligned}
$$

In the last expression, $\mu$ corresponded to the genetic difference: subcohort of clones - subcohort of singles (for the same year of birth).

In the nucleus, $V_{A F}$ represented the pooled genetic variance between single heifers and distinct clones altogether ( $i e, V_{A F}$ is larger than the genetic variance between unselected heifers, since some of them are replicates). $V_{A F}$ can be calculated from the same formula as for males by replacing $W_{i}$ by $W_{i}^{*}$ (reduction of variance after selection among the estimated breeding values of dams of group $i$ females), $m_{i}$ by $f_{i}, M$ by $F+c F^{\prime}, t_{i}$ by $t_{i}^{*}$.

Reasoning after asymptotic equilibrium was obtained, it can be shown that:

$$
\begin{aligned}
\mu=a / b, \text { where } a & =\frac{c}{F^{\prime}} \sum_{i=3,6} f_{i} \rho_{i} I_{t_{i}}-\frac{1}{F} \sum_{i=1,2,4,5} f_{i} \rho_{i} I_{t_{i}} \\
& =\Delta G\left[\frac{L_{1}\left(f_{1}+f_{4}\right)+L_{2}\left(f_{2}+f_{5}\right)}{F}-L_{3}\right] \\
\text { and } \quad b & =2-\frac{c}{F^{\prime}} f_{6}+\frac{1}{F}\left(f_{4}+f_{5}\right)
\end{aligned}
$$

This led to the prediction that $\mu$ is negative (about $-0.5 \Delta G$ ) ie, single born animals are better than clones. This predicted value agreed well with Monte-Carlo simulations. 
As for the previous study on optimizing embryo sexing only, optimization was carried out at two levels, within and between sets of genetic parameters, until predicted genetic gains and genetic parameters eventually stabilized.

\section{Simulation of the asymptotic rate of genetic gain under a Bulmer model}

Single performances were generated by adding a random environmental effect (constant variance equal to 3 ), to a genetic effect (initial genetic variance equal to 1 ) which corresponded to the average parental breeding value plus a random within family segregation effect (constant variance equal to 0.5 ). This last assumption was introduced for the sake of consistency when comparing results with Bulmer's predictions.

Clonal performances were generated in the same way except that the environmental variance for the average of the $\gamma_{1} c$ animals involved in the same clone was equal to $3 / \gamma_{1} c$.

The selection pressures and groups sizes used for the Monte-Carlo simulations were those given by the optimization procedure under a deterministic Bulmer model, for the same set of technical parameters.

The response to superovulation was simulated exactly in the same manner as in the prediction, $i e$, a probability of non-response equal to 0.3 and for responding cows, a constant number of transferable embryos. The number of embryos used for describing the situations corresponded to the average number of embryos for all cows, as in the prediction.

The asymptotic rates of gain were evaluated between annual cohorts 90 and 100 (starting from an unselected population at cohort zero). The regression coefficient of the average points on year was then measured. Each average point represented the average of 200 replicates for every scheme.

\section{Accounting for inbreeding}

Though the main predicting algorithm and the previous Monte-Carlo simulations assumed a constant within family genetic variance, this assumption was removed during some additional Monte-Carlo simulations where this variance was multiplied by $1-\frac{1}{2}\left(F_{S}+F_{D}\right)$ where $F_{S}$ and $F_{D}$ were the inbreeding coefficients for sire and dam respectively. The objective of these additional computations was to examine whether ranking between alternative schemes could be significantly affected when moving towards more realistic examination of the results and to throw some light on possible future studies about how to use cloning.

In our layout, overlapping generations during 100 years led to heavy manipulations on kinship matrices. To save computations time and storage, these additional Monte-Carlo simulations were restricted to situations where the number of genetically different dams were rather limited (fewer than 100 per annual cohort of potential dams). 


\section{Situations investigated}

Given that each physically different donor provided 8 or 10 embryos (after 2 collections) the survival rate of which was 0.4 or 0.6 , situations were investigated where 1000 embryos, 2000 embryos and 4000 embryos were transferred to recipients. Within each such situation, variations for the number of live members per female clone were introduced. The overall range of this number ( $c$ in the equations) was 3 , $5,10,20,30$.

\section{RESULTS}

\section{Bulmer predictions for moderate cloning}

Table III shows the results obtained by optimizing sexing and cloning with 3 or 5 members per clone. These results are those of the asymptotic genetic gain including Bulmer effect but excluding inbreeding effect. Taking the $S$ scheme (embryo sexing only) as a reference, it can be observed that this asymptotic genetic gain can still be enhanced after optimizing the relative proportions of single and clonal populations, and the corresponding selection pressures. The order of magnitude is $+6 \%$ for $c=3$ and $+11 \%$ for $c=5$.

Table III. Predicted absolute annual genetic gains (in $10^{-3}$ of initial genetic standard deviation) according to the breeding scheme ( $S$, with embryo sexing; $S C$, with embryo sexing and cloning), the number of embryos per collection, the embryo survival rate, the overall number of transferred embryos.

\begin{tabular}{|c|c|c|c|c|c|c|}
\hline \multirow[t]{2}{*}{ Situation } & \multirow{2}{*}{$\begin{array}{l}\text { Transferred } \\
\text { embryos }\end{array}$} & \multirow{2}{*}{$\begin{array}{l}\text { Embryos } \\
\text { per } \\
\text { collection }\end{array}$} & \multirow{2}{*}{$\begin{array}{c}\text { Embryo } \\
\text { survival } \\
\text { rate }\end{array}$} & \multicolumn{3}{|c|}{ Scheme } \\
\hline & & & & $S$ & $\begin{array}{c}S C \\
3 \mathrm{~m} / \text { clone }\end{array}$ & $\begin{array}{c}S C \\
5 \mathrm{~m} / \text { clone }\end{array}$ \\
\hline 1 & & 4 & 0.4 & 212 & 226 & 233 \\
\hline 2 & 1000 & & 0.6 & 222 & 235 & 245 \\
\hline 3 & & 5 & 0.4 & 214 & 228 & 236 \\
\hline 4 & & & 0.6 & 224 & 238 & 248 \\
\hline 5 & & 4 & 0.4 & 222 & 235 & 244 \\
\hline 6 & 2000 & & 0.6 & 230 & 244 & 255 \\
\hline 7 & & 5 & 0.4 & 224 & 237 & 247 \\
\hline 8 & & & 0.6 & 231 & 246 & 258 \\
\hline 9 & & 4 & 0.4 & 228 & 243 & 254 \\
\hline 10 & 4000 & & 0.6 & 236 & 251 & 264 \\
\hline 11 & & 5 & 0.4 & 231 & 245 & 257 \\
\hline 12 & & & 0.6 & 239 & 254 & 264 \\
\hline
\end{tabular}

Table IV show that even for $c=3$, the optimal balance for clones is very large. Young heifers are overwhelmingly clones or born from clones. A very high proportion 
Table IV. Detailed distribution of replacement heifers and bulls (assuming 5 embryos per collection, 0.6 survival rate) according to the overall number of transferred embryos and the number of members per clone.

\begin{tabular}{|c|c|c|c|c|c|c|}
\hline & \multicolumn{2}{|c|}{1000 embryos } & \multicolumn{2}{|c|}{2000 embryos } & \multicolumn{2}{|c|}{4000 embryos } \\
\hline & $\begin{array}{c}3 \\
\text { members }\end{array}$ & $\begin{array}{c}5 \\
\text { members }\end{array}$ & $\begin{array}{c}3 \\
\text { members }\end{array}$ & $\begin{array}{c}5 \\
\text { members }\end{array}$ & $\begin{array}{c}3 \\
\text { members }\end{array}$ & $\begin{array}{c}5 \\
\text { members }\end{array}$ \\
\hline Replacement heifers & 622 & 549 & 1284 & 1153 & 2609 & 2343 \\
\hline$\%$ Cloned & 79 & 89 & 81 & 90 & 81 & 90 \\
\hline Replacement clones & 164 & 98 & 346 & 207 & 708 & 424 \\
\hline Group 1 & 7 & 2 & 5 & 1 & 3 & 0 \\
\hline Group 2 & 2 & 0.5 & 1 & 0 & 0 & 0 \\
\hline Group 3 & 1 & 0.2 & 0.5 & 0 & 0 & 0 \\
\hline Group 4 & 38 & 39 & 45.5 & 45 & 52 & 51 \\
\hline Group 5 & 18 & 19 & 17 & 18 & 17 & 18 \\
\hline Group 6 & 34 & 39.3 & 31 & 36 & 28 & 31 \\
\hline \% Replacements heifers & & & & & & \\
\hline Group 1 & 2 & 0.4 & 2 & 0.5 & 2 & 0 \\
\hline Group 2 & 1 & 0 & 1 & 0 & 1 & 0 \\
\hline Group 3 & 8 & 1.6 & 7 & 1.5 & 7 & 0 \\
\hline Group 4 & 11 & 7 & 11 & 7 & 11 & 7 \\
\hline Group 5 & 6 & 3 & 5 & 3 & 5 & 3 \\
\hline Group 6 & 72 & 88 & 74 & 88 & 74 & 90 \\
\hline$\%$ Males from clones & 90 & 97 & 93 & 99 & 97 & 100 \\
\hline$\%$ Females from clones & 89 & 98 & 90 & 98 & 90 & 100 \\
\hline
\end{tabular}

of males is born from clones. However, the overall number of distinct clones born in a given year is not negligible (at least 98 in these examples).

The basic facts explaining such a result are that clones are similar to dummy cows with much higher accuracy of estimated breeding values and with much higher reproductive potential: good genotypes can be found this way and disseminated into the nucleus breeding population later on. Under these conditions, breeding status of female clones resembles its counterpart on the male side.

Table $\mathrm{V}$ shows that only a small proportion of single cows are selected, a consequence of a lower selection accuracy. However, clonal selection intensities are still very high. Combined with a high selection accuracy, this is the reason for the success of clonal selection $v s$ single selection.

\section{Verification through Monte-Carlo simulations}

The simulations were carried out during a very long time span $i e, 100$ years, starting from the no selection situation. The detailed results showed that the asymptotic regime was not obtained before year 50 because of the erratic variations occuring during the first years of any breeding scheme, the relatively long generation interval and the progressive influence of the Bulmer effect. Consequently, the estimated asymptotic parameters can be safely considered. 
Table V. Single selection pressure or clonal selection pressure (\%) on dams of different groups of replacement males or females, assuming 5 embryos per collection, 0.6 survival rate (see table IV).

\begin{tabular}{|c|c|c|c|c|c|c|}
\hline & \multicolumn{2}{|c|}{1000 embryos } & \multicolumn{2}{|c|}{2000 embryos } & \multicolumn{2}{|c|}{4000 embryos } \\
\hline & $\begin{array}{c}3 \\
\text { members }\end{array}$ & $\begin{array}{c}5 \\
\text { members } \\
\end{array}$ & $\begin{array}{c}3 \\
\text { members }\end{array}$ & $\begin{array}{c}5 \\
\text { members }\end{array}$ & $\begin{array}{c}3 \\
\text { members }\end{array}$ & $\begin{array}{c}5 \\
\text { members }\end{array}$ \\
\hline \multicolumn{7}{|c|}{ Dams of males } \\
\hline \multicolumn{7}{|c|}{ Single selection pressure } \\
\hline Group 1 & 17 & 14 & 6 & 4 & 2 & - \\
\hline Group 2 & 5 & 3 & 1 & 0.5 & 0.3 & - \\
\hline Group 3 & 0.6 & 0.2 & 0.1 & - & - & - \\
\hline \multicolumn{7}{|c|}{ Clonal selection pressure } \\
\hline Group 4 & 25 & 25 & 14 & 14 & 8 & 8 \\
\hline Group 5 & 13 & 14 & 6 & 6 & 3 & 3 \\
\hline Group 6 & 4 & 5 & 2 & 2 & 0.8 & 0.9 \\
\hline \multicolumn{7}{|c|}{ Dams of females } \\
\hline \multicolumn{7}{|c|}{ Single selection pressure } \\
\hline Group 1 & 30 & 8 & 27 & 7 & 26 & - \\
\hline Group 2 & 11 & - & 10 & - & 9 & - \\
\hline Group 3 & 6 & 0.1 & 6 & 1 & 6 & - \\
\hline \multicolumn{7}{|c|}{ Clonal selection pressure } \\
\hline Group 4 & 36 & 20 & 34 & 19 & 33 & 18 \\
\hline Group 5 & 20 & 10 & 18 & 9 & 17 & 9 \\
\hline Group 6 & 14 & 9 & 14 & 9 & 14 & 9 \\
\hline
\end{tabular}

Examination in table VI of the inbreeding-free simulations for the situations where 5 embryos were obtained per donor and per collection, and with a survival rate equal to 0.6 , shows that the realized annual genetic gains between years 90 and 100 were substantially lower than the predicted ones (5 to $14 \%$ ). $c$ was then allowed to vary according to the following pattern: $3,5,10,20,30$.

Table VI. Simulated values for the asymptotic genetic gains expressed in $10^{-3}$ of the initial genetic standard deviation or in $\%$ of the predicted value (within brackets) assuming 5 embryos per collection, 0.6 survival rate.

\begin{tabular}{llll}
\hline $\begin{array}{l}\text { Members per } \\
\text { clone } \\
(c)\end{array}$ & \multicolumn{3}{c}{ Transferred embryos } \\
\cline { 2 - 4 } & 1000 & 2000 & 4000 \\
\hline 3 & $219(93)$ & $229(93)$ & $240(95)$ \\
5 & $230(93)$ & $242(94)$ & $248(94)$ \\
10 & $242(93)$ & $259(95)$ & $268(95)$ \\
20 & $248(91)$ & $262(92)$ & $278(93)$ \\
30 & $236(86)$ & $269(92)$ & $281(92)$ \\
\hline
\end{tabular}


The discrepancy is similar to that found for the embryo sexing schemes, under the same genetic assumptions (Colleau, 1991), except for situations where the predicting algorithm utilizes misleading selection pressures obtained with fractional clones (ie, less than 1 clone provides all the replacement animals, given the total reproductive capacity of this clone). This is the case for the situations with 1000 embryos transferred and $c \geq 10$. Giving up the basic assumption that selection pressures are continuous functions, in order to adopt a more realistic stepwise function is useful for extreme situations but hampers numerical optimization for more general cases.

\section{Accounting for inbreeding effects}

When cloning females, the useful number of dams decreases and therefore, inbreeding is expected to increase.

Table VII shows that limiting reproductive capacity of clones below that theoretically achievable in order to reduce increases in inbreeding, would lead to a significant drop of genetic gains. If the overall capacity of such clones corresponds approximately to the capacity of a single cow, no advantage could be found when comparing with embryo sexing. This observation emphasizes the role of reproductive capacity in such schemes.

Table VII. Effects of a partial use of the clonal reproductive capacity on the predicted asymptotic genetic gains (same units as in table VI) assuming 5 embryos per collection and 0.6 survival rate.

\begin{tabular}{lcccc}
\hline $\begin{array}{l}\text { Members } \\
\text { per } \\
\text { clone }\end{array}$ & $\begin{array}{c}\text { Clonal } \\
\text { reproductive } \\
\text { capacity } \\
\text { (\% maximum) }\end{array}$ & 1000 & 2000 & 4000 \\
\cline { 2 - 4 } & 100 & 238 & 246 & 264 \\
3 & 50 & 226 & 234 & 241 \\
& 33 & 223 & 230 & 236 \\
5 & 100 & 248 & 258 & 254 \\
5 & 50 & 231 & 242 & 250 \\
& 20 & 223 & 230 & 236 \\
Embryo sexing only & & 224 & 231 & 239 \\
\hline
\end{tabular}

Realistic genetic gains were observed between years 90 and 100 for situations where $c=5$ or 10 (table VIII) after implementing Monte-Carlo simulations including inbreeding effects. It was clear that a very significant drop (about $-20 \%$ ) occurred when compared to the corresponding inbreeding-free Monte-Carlo simulations. This result is not surprising due to the long time span, and the final inbreeding coefficients $(0.20-0.25)$ that affect genetic variances very much.

The annual inbreeding rates obtained for $c=5$ are primarily the result of using a limited number of sires ( 3 per year $i e$, about 15 per generation). Nevertheless, this number might be close to the optimum for long term genetic gains according to the results of Goddard and Smith (1990). 
Table VIII. Results of Monte-Carlo simulations accounting for inbreeding ( 5 embryos per collection, 0.6 survival rate): 200 replicates per situation.

\begin{tabular}{llll}
\hline $\begin{array}{l}\text { Members } \\
\text { per } \\
\text { clone }\end{array}$ & \multicolumn{3}{c}{ Transferred embryos } \\
\cline { 2 - 4 } & 1000 & 2000 & 4000 \\
\hline 3 & $\mathrm{a} 172(79)$ & \multicolumn{2}{c}{ Not investigated } \\
& $\mathrm{b} 18.2$ & & \\
& $\mathrm{c} 0.22 \%$ & $190(78)$ & $202(81)$ \\
& $\mathrm{d} 0.19$ & 20.2 & 21.9 \\
5 & $182(79)$ & $0.25 \%$ & $0.22 \%$ \\
& 19.1 & 0.21 & 0.20 \\
& $0.25 \%$ & $199(77)$ & $211(79)$ \\
10 & 0.21 & 21.3 & 22.4 \\
& $183(75)$ & $0.29 \%$ & $0.27 \%$ \\
& 19.9 & 0.25 & 0.23 \\
\hline
\end{tabular}

a Observed annual genetic gains between years 90 and 100 in $10^{-3}$ of the initial genetic standard deviation or in \% of the corresponding inbreeding-free Monte-Carlo values (in parentheses); ${ }^{b}$ Average breeding values in year 100 (unit: initial genetic standard deviation); ${ }^{c}$ Annual inbreeding rate between years 90 and $100 ;{ }^{d}$ Average inbreeding coefficient in year 100 .

If selection were at random and if a very large number of females were used, the annual inbreeding rates would be around $0.17 \%\left(1 / 24 L^{2}\right)$, where $L$ is the interval between generations).

Table VIII shows that going from $c=5$ to $c=10$ led to a substantial increase of the asymptotic annual inbreeding rates. However, even after 100 years, instantaneous genetic gains were still higher with $c=10$, despite a larger discrepancy with the predicted results under a Bulmer model. The cumulated superiority of the situation $c=10 v s c=5$ corresponded to about 1 initial genetic standard deviation. The relative advalutage of cloning more intensively was all the more clear as the overall number of females is higher (high overall number of transferred embryos).

\section{DISCUSSION}

The previous results showed that embryo sexing and cloning might be used for breeding purposes within nuclei, as already suggested for beef cattle by Smith (1989). Even with the severe constraint of a constant overall number of transferred embryos, some cloning might enhance rates of genetic gain due to better selection accuracy and prolificacy of female genotypes. This is not contradictory to previous results on conventional ET, showing that genetic gains increase with prolificacy coming from high superovulation rates (Nicholas and Smith, 1983; Colleau, 1985; Meuwissen, 1990).

The complexity of current algorithms for predicting $F$ values under selection (Wray and Thompson, 1990 and Verrier et al, 1990, 1991) prevented correct 
adjustment of predicted genetic gains for these values and subsequent algebraic optimization. Therefore, no analytical solution was proposed for finding the optimum size of a given clone for breeding purposes. Predictions under the Bulmer effect led to the finding that genetic gains were larger as clone size increased. It can be questioned that the optimum number of clones is 1 since high values for $F$ would be deleterious for genetic gains.

The observations coming from Monte-Carlo simulations accounting for inbreeding were very interesting since they showed that additional genetic gains could still be obtained after changing from 5 members (live females) per clone to 10 members per clone. Therefore, keeping only 5 members (moderate cloning) would probably not be a bad solution because this situation is still in the ascending part of the curve of genetic gains. In comparison with pure embryo sexing without cloning, the superiority of such a scheme could correspond to about $10 \%$ of genetic gain. It should be mentioned that in this situation, the optimum organization becomes very simple, since all the male and female replacements come from cloned females superovulated during lactation 2 .

It is not certain that this finding could be generally obtained in every kind of MOET on dairy cattle. Some characteristics of the schemes analysed here allow them to take profit from cloning without suffering too much of its main drawback, ie a virtual lift for inbreeding rates. Indeed, annual inbreeding rates are not too excessive (around $0.25 \%$ ) because of relatively long interval between generations (around 5 years), and of relatively high numbers of dams per generation. When considering the situations " 5 members per clone" for tables IV and V, the number of female clones per generation used for providing dams is about 50 for 1000 embryos, 100 for 2000 embryos and 200 for 4000 embryos. This rough estimate corresponds to the number of years per generation (5) multiplied by the annual number of new clones candidates for selection and by the selection pressure used for providing the larger group of females (group 6). Furthermore, selection on performance for females rather than on EBVs has been already referred to as a way to moderate inbreeding increases, ie protecting long-term genetic gains while obtaining good short-term gains (Dempfle, 1990; Senou, 1990; Toro and Perez-Enciso, 1990; Verrier et al, 1991). Analytical optimization becomes easier in such a case. To end with, it should be recalled that any cloning of sires in such schemes would be detrimental, since the limited number of sires already explains the major part of inbreeding, before any cloning.

Inbreeding depression might affect performances as well, if non-additive (eg, dominance) genetic variation occurs $i e$, a situation not envisioned here. Taking inbreeding depression into account would lead to change the genetic model and to adapt the prediction theory accordingly.

Given the numerous precautions alluded to previously, embryo cloning might be considered as a 2 sided activity: the first side corresponding to detection and utilization of good female clones for breeding purposes within selection nuclei, the second side (not considered here) corresponding to a larger diffusion of the very best clones into the commercial populations (supposing that recloning of stored embryos is technically feasible). Moving from one to the other would require no additional testing: a clone known from the performances of 5 members would represent a good security for breeders (selection accuracy around 0.79 ). The unique possibility given 
by cloning to diffuse the very best of accurately known females (thus contributing to dairy economy) should be stressed, even in the case where the annual genetic gains are unaffected. The fact that these genetic gains seem to be slightly improved in addition allows one to keep this conclusion.

A major part of the present findings and of the corresponding recommendations for a possible future implementation within and outside selection nuclei does not coincide with those of previous works on embryo cloning in dairy cattle and showing small losses on genetic gains (Teepker and Smith, 1989; Woolliams, 1980; De Boer and Van Arendonk, 1991). Because no cloning was recommended within the nucleus, the question about how to improve the accuracy of evaluation on clones disseminated into commercial herds remained open, contrarily to the present study. It can be assumed that the set of constraints used has a major impact on the results obtained. The afore-mentioned researchers set up their constraints on fixed numbers of recorded females (testing capacity) and most of all, fixed numbers of sires and dams. Subsequent introduction of cloning in this context led to substantial decreases of selection intensities. Here, recorded females were supposed to be dispersed among conventional farms, as part of a regular milk recording scheme, so that the overall number of transferred embryos could be chosen as the main constraint. Furthermore, the number of dams was not fixed but owing to the moderate cloning rate envisioned, no major consequences on inbreeding rates ensued.

\section{APPENDIX}

Derivatives needed for optimizing the genetic gains (nucleus with embryo sexing and cloning

$\rho_{1}, m_{i}, f_{i}, \theta_{i}, \theta_{i}^{*}, t_{i}, t_{i}^{*}, p_{i}, p_{i}^{*}, I_{t_{i}}, I_{t_{i}^{*}}, \phi_{t_{i}}, \phi_{t_{i}^{*}}, M, F, F^{\prime}, c$ are defined in the main text.

Let us define

$$
\begin{aligned}
& F+c F^{\prime}=T \\
& \varepsilon_{i}=\theta_{i} \rho_{i} \quad \varepsilon_{i}^{*}=\theta_{i}^{*} \rho_{i} \\
& \omega=\sum_{i=1}^{3} \varepsilon_{i}^{*} p_{i}^{*} t_{i}^{*} \quad \omega^{\prime}=\sum_{i=4}^{6} \varepsilon_{i}^{*} p_{i}^{*} t_{i}^{*} \\
& \mu=c \sum_{i=1}^{3} \varepsilon_{i}^{*} \phi_{t_{i}^{*}}-\sum_{i=4}^{6} \varepsilon_{i}^{*} \phi_{t_{i}^{*}} \\
& \alpha=\frac{1}{M} \sum_{i=1}^{3} \varepsilon_{i}\left(\phi_{t_{i}}-p_{i} t_{i}\right)-\frac{\omega}{T}+\frac{\mu F^{\prime}}{T^{2}} \\
& \alpha^{\prime}=\frac{1}{M} \sum_{i=4}^{6} \varepsilon_{i}\left(\phi_{t_{i}}-p_{i} t_{i}\right)-\frac{\omega^{\prime}}{T}-\frac{\mu F}{T^{2}} \\
& \beta=\left(F \sum_{i=1}^{3} \theta_{i}^{*} L_{i} p_{i}^{*}+F^{\prime} \sum_{i=4}^{6} \theta_{i}^{*} L_{i} p_{i}^{*}\right) / T^{2}
\end{aligned}
$$


$\Delta G$, the asymptotic annual genetic gain is equal to the ratio $u / v$ where the full expression of $u$ and $v$ is given in the Materials and Methods.

The first derivatives of $u$ and $v$ with respect to $m_{1}, m_{2}, m_{3}, m_{4}, m_{6}, f_{1}, f_{2}, f_{3}, f_{4}, f_{5}$ are very simple:

$$
\begin{gathered}
\delta u / \delta m_{1}=\frac{1}{M}\left(\rho_{1} t_{1}-\rho_{5} t_{5}\right) ; \delta u / \delta m_{2}=\frac{1}{M}\left(\rho_{2} t_{2}-\rho_{5} t_{5}\right) \\
\delta u / \delta m_{3}=\frac{1}{M}\left(\rho_{3} t_{3}-\rho_{5} t_{5}\right)-\frac{\rho_{6} t_{6}}{T}-\frac{\alpha^{\prime}}{c} ; \delta u / \delta m_{4}=\frac{1}{M}\left(\rho_{4} t_{4}-\rho_{5} t_{5}\right) \\
\delta u / \delta m_{6}=\frac{1}{M}\left(\rho_{6} t_{6}-\rho_{5} t_{5}\right)-\frac{\rho_{6} t_{6}}{T}-\frac{\alpha^{\prime}}{c} ; \delta u / \delta f_{1}=\frac{\rho_{1} t_{1}^{*}}{T}+\alpha \\
\delta u / \delta f_{2}=\frac{\rho_{2} t_{2}^{*}}{T}+\alpha ; \delta u / \delta f_{3}=\frac{\rho_{3} t_{3}^{*}-\rho_{6} t_{6}^{*}}{T} \\
\delta u / \delta f_{4}=\frac{\rho_{4} t_{4}^{*}}{T}+\alpha ; \delta u / \delta f_{5}=\frac{\delta_{5} t_{5}^{*}}{T}+\alpha \\
\delta v / \delta m_{1}=\frac{L_{1}-L_{2}}{M} ; \delta v / \delta m_{2}=0 \\
\delta v / \delta m_{3}=\beta+\frac{L_{3}-L_{2}}{M}-\frac{L_{3}}{T} ; \delta v / \delta m_{4}=\delta v / \delta m_{1} ; \delta v / \delta m_{6}=\delta v / \delta m_{3} \\
\delta v / \delta f_{1}=-\beta+\frac{L_{1}}{T} ; \delta v / \delta f_{2}=-\beta+\frac{L_{2}}{T} \\
\delta v / \delta f_{3}=0 ; \delta v / \delta f_{4}=\delta v / \delta f_{1} ; \delta v / \delta f_{5}=\delta v / \delta f_{2}
\end{gathered}
$$

The second derivatives were obtained from the general expression of the derivatives of $u$ or $v$ according to any couple of variates $(x, y)$. This procedure led to rather cumbersome expression (available on request to the author) but easy to implement since the first derivatives $\delta F / \delta x, \delta F^{\prime} / \delta x, \delta m_{i} / \delta x, \delta f_{i} / \delta x$ are straightforward $(1,-1,0$, or $-1 / c$ depending on the case).

\section{ACKNOWLEDGMENTS}

Two anonymous reviewers are acknowledged for useful suggestions.

\section{REFERENCES}

Bulmer MG (1971) The effect of selection on genetic variability. Am Nat 105, 201211

Colleau JJ (1985) Efficacité génétique du transfert d'embryons dans les noyaux de sélection chez les bovins laitiers. Genet Sel Evol 17, 499-538

Colleau JJ (1991) Using embryo sexing within closed mixed MOETs for selection on dairy cattle. J Dairy Sci 74, 3973-3984

De Boer IJM, Van Arendonk JAM (1991) Genetic and clonal responses in closed dairy cattle nucleus schemes. Anim Prod 53, 1-9

Dempfle L (1990) Statistical aspects of design of animal breeding programs: a comparison among various selection strategies. In: Advances in Statistical Methods 
For Genetic Improvement of Livestock (Gianola D, Hammond K, eds) Springer Verlag, Berlin 98-117

Goddard MG, Smith C (1990) Optimum number of bull sires in dairy cattle breeding. J Dairy Sci 73, 1113-1122

Meuwissen THE (1990) The use of increased female reproductive rates in dairy cattle breeding schemes. Anim Prod 52, 21-31

Nicholas FW, Smith C (1983) Increased rates of genetic changes in dairy cattle by embryo transfer and splitting. Anim Prod 36, 341-353

Rendel JM, Robertson A (1950) Estimation of genetic gain in milk yield by selection in nuclei in a close herd of dairy cattle. $J$ Genet $50,1-8$

Scales LE (1985) Introduction to Non-Linear Optimization. Macmillan Publ Ltd, London, UK

Senou M (1990) Untersuchung über die Entwicklung der additiv-genetischen Varianz und der Inzucht sowie der erzielbaren kurz- and langfristigen Selektionserfolge in geschlossenen Nukleuszuchtprogrammen. Dissertation, Technische Universität München, Munich, $140 \mathrm{pp}$

Smith C (1989) Cloning and genetic improvement of beef cattle. Anim Prod 49, 49-62

Teepker G, Smith C (1989) Combining clonal response and genetic response in dairy cattle improvement. Anim Prod 49, 163-169

Toro MA, Perez-Enciso M (1990) Optimizing selection under restricted inbreeding. Genet Sel Evol 22, 93-107

Van Vleck LD (1981) Potential genetic impact of artificial insemination, sex selection, embryo transfer, cloning and selfing in dairy cattle. In: New Technologies in Animal Breeding (Bracket BC, Seidel GE, Seidel SM, eds) Acad Press, London, $221-242$

Verrier E, Colleau JJ, Foulley JL (1990) Predicting cumulated response to directional selection in finite panmictic populations. Theor Appl Genet 79, 833-840

Verrier E, Colleau JJ, Foulley JL (1991) Methods for predicting response to selection is small populations under additive genetic model: a review. Livest Prod Sci 29, 93114

Woolliams JA (1989) The value of cloning in MOET nucleus breeding schemes for dairy cattle. Anim Prod 48, 31-35

Wray NR, Thompson R (1990) Prediction of rates of inbreeding in selected population. Genet Res Camb 55, 41-54 